\title{
Comparative study between digital and conventional fingerprinting using addition silicone
}

\author{
Studiu comparativ între amprentarea digitală şi convenţională \\ folosind siliconul de adiţie
}

\author{
Bogdan Mihai Gălbinaşu', Andrei Iulian Păcuraru², Ion Pătraşcu' ${ }^{1}$ \\ ${ }^{1}$ Materiale Dentare şi Tehnologia Protezelor Dentare, \\ Universitatea de Medicină şi Farmacie „Carol Davila“, Bucureşti, Romania \\ ${ }^{2}$ Cabinet stomatologic, Ploieşti, România
}

\begin{abstract}
The accuracy of digital models and digital impressions influence the clinical restorations. The aim of this study is to compare digital impression and the analog one, using time as the variable. Materials used for the classic stage were: acrylic cast resin, impression tray, impression material (EliteHD), extruded gypsum (Elite), vacuum mixer, and vibrating table. For digital impression there were used: acrylic cast resin, gypsum cast, scanning system Identica Blue, analysis software for virtual casts. The applied method consisted on using a cast of upper jaw, made of acrylic resin, on which were prepared type II cavities. After scanning this cast, it was obtained a virtual cast which was considered a reference as time $x$. Using the acrylic cast resin, there were taken impressions with addition silicon on tray, one stage, four different times. After that it was made the gypsum casts which will be scanned and turned into virtual as a STL file. The four STL files, after the four gypsum casts, and the reference cast at time $\mathrm{x}$, were compared on sagitall and transverse planes, by making measurements on the preparation sites. Dimensions obtained after digital measurements vary during the selected period of time on both planes in order of tens of microns. Classic impression with addition silicon might be used as another way to have an impression than the digital one, regarding the dimensional stability and precision in detail reproduction.
\end{abstract}

Keywords: impression, digital, Identica Blue scanner, pvs

\section{REZUMAT}

Precizia modelelor digitale şi amprentarea digitală influenţează calitatea restaurărilor finale. Scopul acestui studiu este de a compara amprentarea digitală cu cea convenţională, având ca variabilă timpul. Materialele utilizate pentru etapa clasică au fost: model din acrilat arcadă superioară, lingură de amprentare standard, material de amprentă (EiteHD), ghips extradur (EliteHD), vacuum malaxor şi măsuţă vibratorie. Pentru etapa digitală s-au folosit model din acrilat, modele din ghips extradur, scanner Identica Blue, software de analiză a modelelor digitale. Metoda aplicată a presupus utilizarea modelului maxilar din acrilat pe care s-au preparat cavităţi de clasa a doua. Acest model a fost scanat şi notat ca model de referinţă la un timp x. Plecând de la modelul de acrilat, s-au înregistrat patru amprente cu silicon de adiţie la patru timpi diferiţi. În urma obţinerii copiilor negative, s-au turnat modele din ghips extradur, care au fost ulterior scanate si transformate în fişiere .STL. Cele patru fişiere .STL şi modelul digital la timpul $x$ au fost măsurate şi comparate în plan sagital şi transversal, rezultând valori de ordinul zecilor de microni. Metoda clasică de amprentare cu silicon de adiţie poate fi folosită ca o altă modalitate de amprentare faţă de cea digitală, din punctul de vedere al stabilitaţii dimensionale şi fidelităţii.

Cuvinte cheie: amprentare, digital, scanner Identica Blue, polivinilsiloxan

\section{INTRODUCERE}

Tehnologia digitală a fost foarte mult influențată de evoluția calculatoarelor şi a imagisticii, care au avut un impact important asupra practicii dentare (1).
A fost acceptată pe scară largă începand cu 1970, când Dr. François Duret a prevăzut posibilitatea utilizării tehnologiei digitale în sfera stomatologică. Acesta a venit cu ideea folosirii laserului pentru obținerea amprentelor dentare optice, ceea 
ce mai târziu a ilustrat un principiu de capturare a informației pentru CAD-CAM. Entuziasmul său nu a fost acceptat cu uşurință de către ceilalți, considerând ideea lui de tehnologizare a stomatologiei nefolositoare şi nejustificabilă (1).

În 1980, profesorul Werner Mormann din Zurich şi Dr. Marco Bondestini au împărtăşit aceeaşi părere cu cea a Dr. François Duret şi au început o serie de experimente. În decembrie 1980, aceştia au folosit pentru prima dată amprentarea digitală pe un pacient. În 1982, primul scanner intraoral a fost realizat, urmând în 1985 să fie disponibil pentru comercializare sub denumirea de Cerec1 RedCam, apoi în 2009 BlueCam si OmniCam astăzi (1).

În prezent, sfera digitală a stomatologiei este în continuă evoluție şi se aşteaptă înlocuirea metodelor clasice de amprentare şi prelucrare pentru obținerea unor lucrări protetice finale $(2,3,4,5)$.

Amprentele cu polivinilsiloxan sunt cele mai utilizate ca metode de amprentare, datorită proprietăților de lucru precum stabilitatea dimensională ridicată şi fidelitatea crescută. În ciuda proprietăților remarcabile, sunt considerate materiale clasice de amprentă, privite cu scepticism de unele laboratoare de tehnică dentară $(3,5,6)$.

Scopul acestui studiu este de a compara metoda digitală de amprentare cu cea convențională, folosind siliconul de adiție şi timpul ca variabilă.

\section{MATERIALE ŞI METODĂ}

Materialele folosite pentru realizarea studiului au fost împărțite în două categorii, digital şi convențional.

Materialele folosite în etapa clasică au fost model din acrilat arcadă superioară, linguri de amprentare standard, material de amprentă (EliteHD), ghips extradur (EliteHD) vacuum malaxor şi măsuță vibratorie.

Pentru etapa digitală s-au folosit model din acrilat arcadă superioară, modele din ghips extradur, scanner Identica Blue, software de analiză a modelelor virtuale.

Metoda de lucru a presupus utilizarea modelului din acrilat arcadă superioară, pe care s-au preparat cavităţi de clasa a doua. După scanarea acestui model s-a obținut o variantă digitală a acestuia, considerată referință la un timp x.

Folosind în continuare acelaşi model din acrilat, s-au înregistrat amprente cu silicon de adiție în lin-

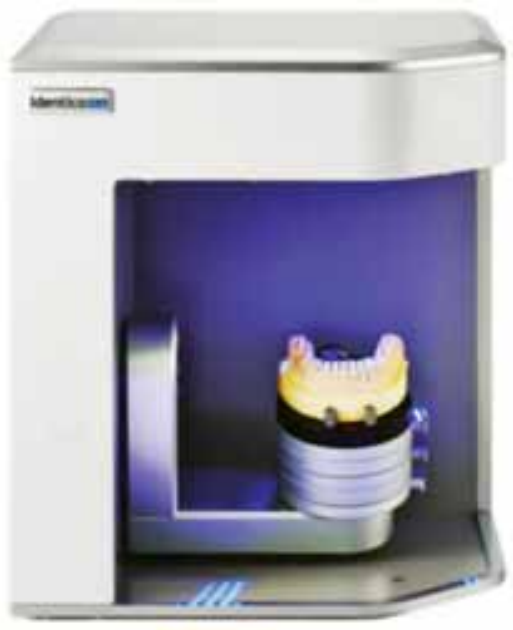

FIGURA 1. Scanner Identica Blue, folosit pentru scanarea modelelor din ghips şi a modelului de referință din acrilat (9)

Specificații:

Sursa de lumină: LED, 50 ANSI-Iumeni

Perimetru de scanare: $80 \times 60 \times 60 \mathrm{~mm}$

Dimensiuni: 290 × $290 \times 340$ mm

Greutate: $16 \mathrm{~kg}$

Erori: $<10$ microns

Formatul fişierelor: STL (9)

Durata unei scanări: 35s

gura standard, două consistențe chitos şi fluid, întrun singur timp pentru patru momente diferite (T0, $\mathrm{T} 1, \mathrm{~T} 2, \mathrm{~T} 3)$.

După obținerea celor patru amprente la patru timpi diferiți, s-au turnat modele din ghips extradur de la aceeaşi firmă cu cea a materialului de amprentă.

Modelele din ghips rezultate vor fi scanate şi transformate în fișiere .STL.

Toate cele patru fişiere rezultate în urma scanării modelelor din ghips, împreună cu cel referință la Tx, au fost măsurate şi comparate în plan sagital şi transversal la nivelul preparațiilor de clasa a doua.

Fişierele. STL au fost deschise şi analizate cu un software independent de sistemul de scanare, 3DToolViewer, ce a facut posibilă măsurarea şi identificarea coordonatelor pe cele trei axe $\mathrm{x}, \mathrm{y}, \mathrm{z}$.

Măsurătorile la nivelul preparațiilor au fost făcute identificând patru puncte cu coordonate $\mathrm{x}, \mathrm{y}, \mathrm{z}$ pentru planul sagital (AA', CC') şi şase puncte pentru planul transversal (BB', DD', FF'). Aceste puncte identificate pe toate modelele digitale au fost unite două câte două, formând segmente de lungimi diferite.

Toate punctele mai sus menționate au fost identificate pe toate cele cinci modele digitale pe intervalul de timp 12-72 ore. 


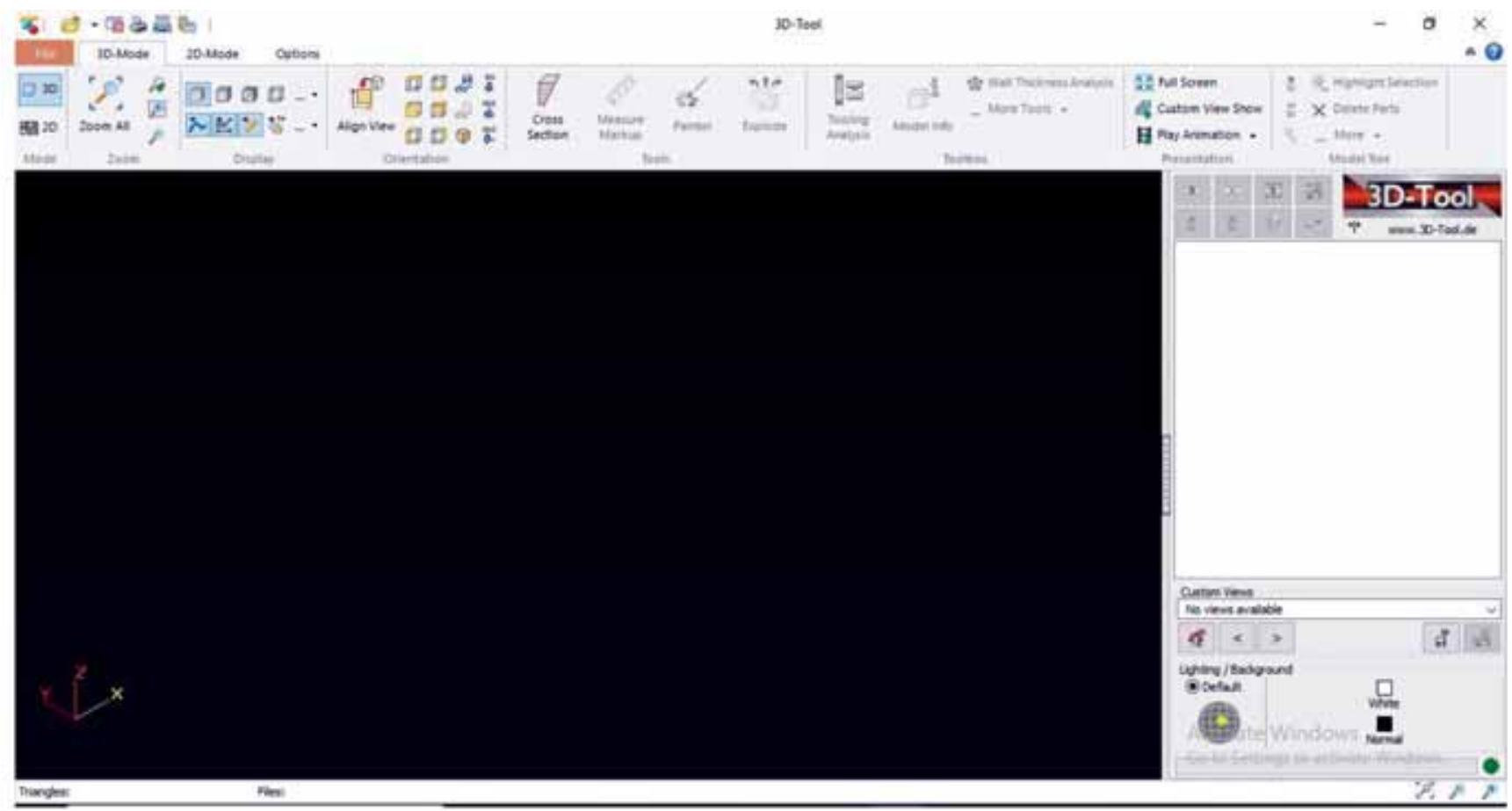

FIGURA 2. Fereastra programului 3DToolViewer, folosit pentru analiza fişierelor .STL

Valorile obținute au fost notate într-un tabel principal (Tabelul 1) şi divizat în două tabele secundare, fiecare pentru câte un plan analizat.

Pe baza acestor tabele s-au reprezentat grafic rezultatele obținute indicând evoluția stabilității dimensionale şi fidelitatea siliconului de adiție pe intervalul de timp ales.

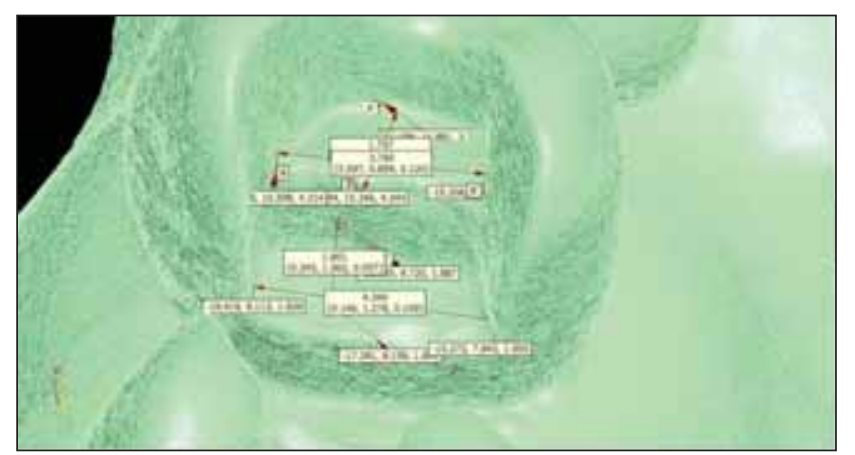

FIGURA 3. Tx Preparația 1.4, măsurători în sens sagital şi transversal
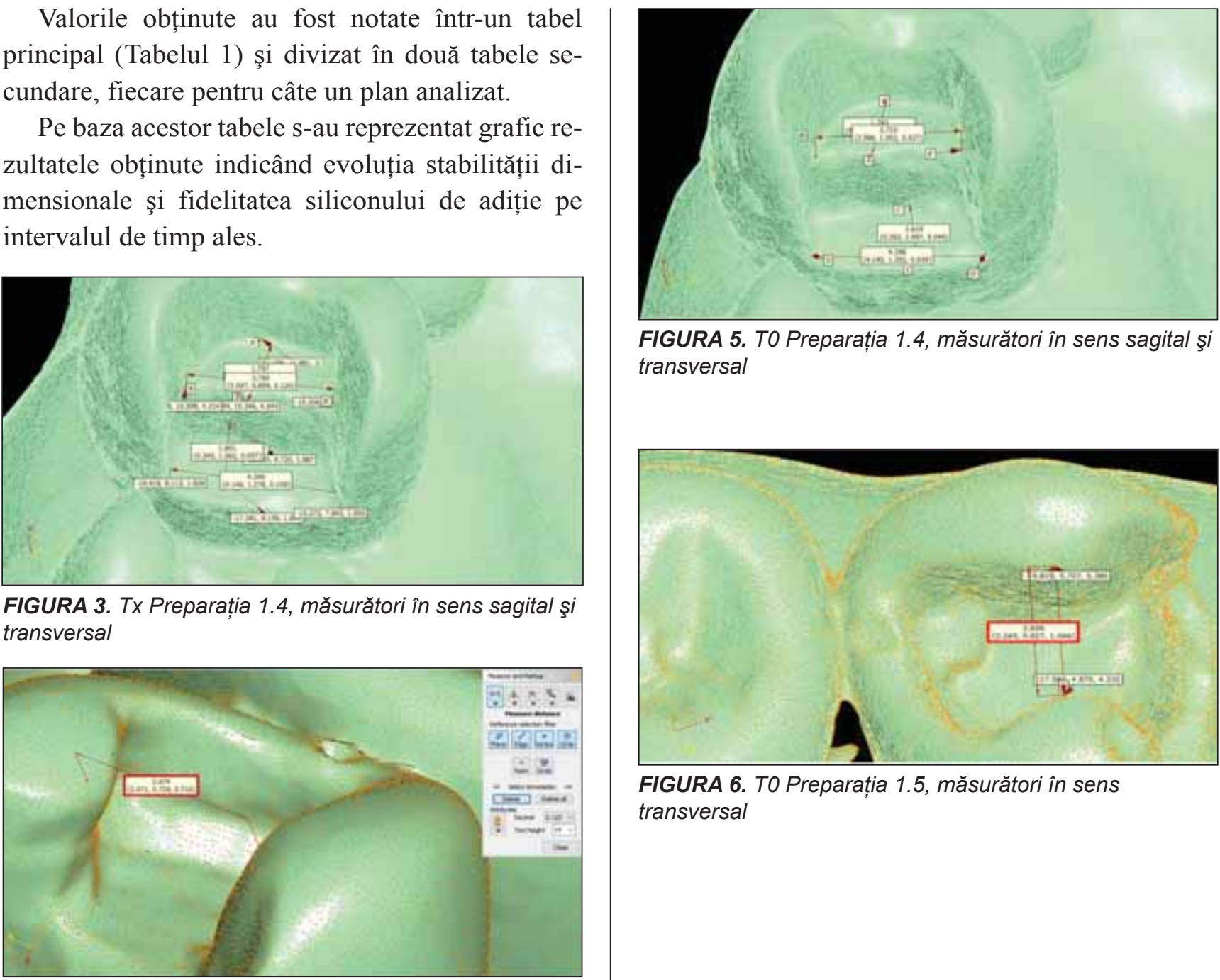

FIGURA 5. T0 Preparația 1.4, măsurători în sens sagital şi transversal

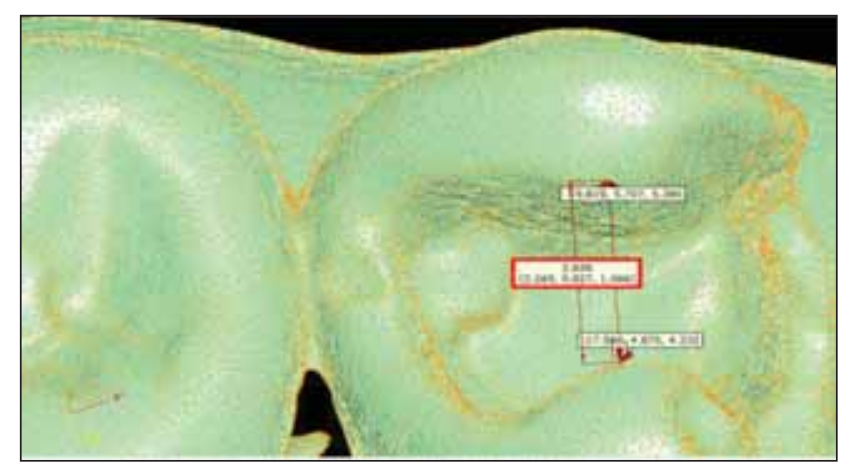

FIGURA 6. TO Preparația 1.5, măsurători în sens transversal

FIGURA 4. Tx Preparația 1.5, măsurători în sens transversal 


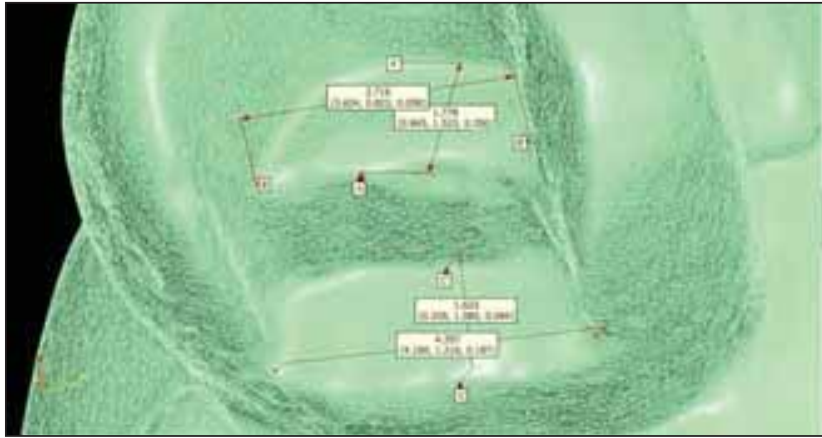

FIGURA 7. T1 Preparația 1.4, măsurători în sens sagital şi transversal

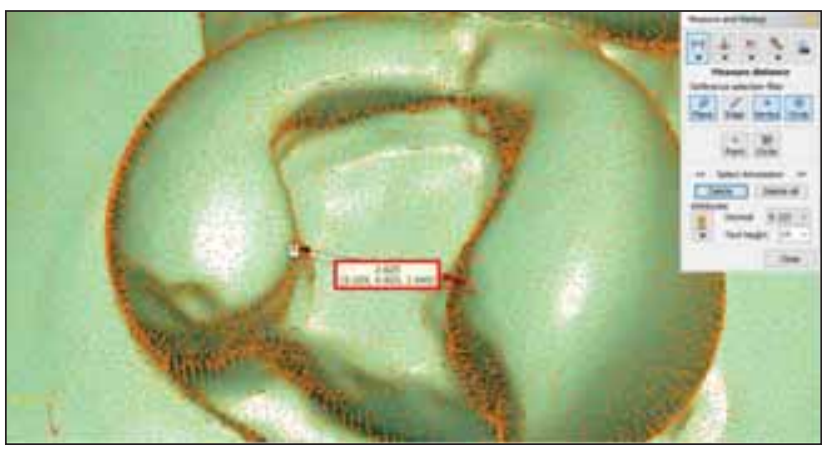

FIGURA 8. T1 Preparația 1.5, măsurători în sens transversal

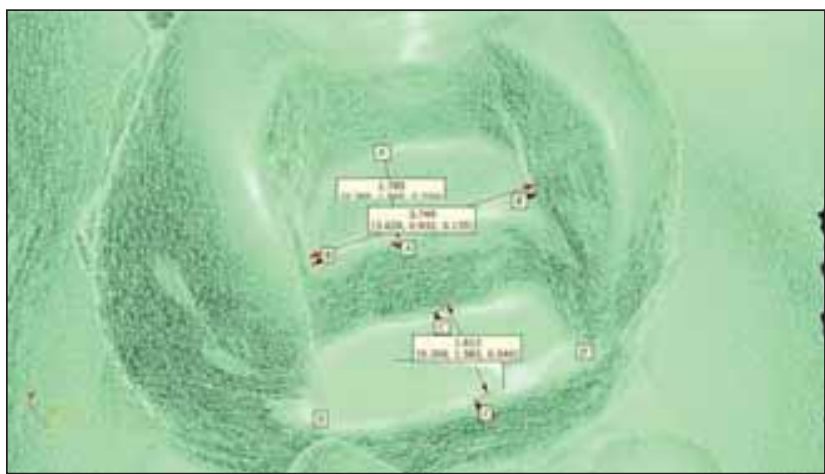

FIGURA 9. T2 Preparația 1.4, măsurători în sens sagital şi transversal

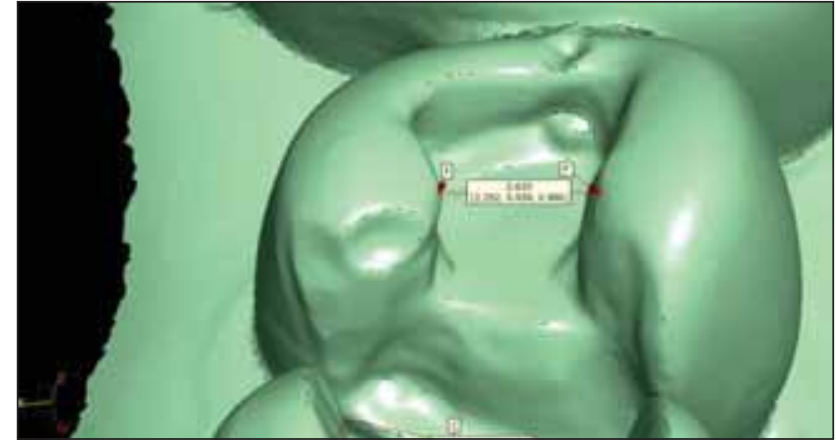

FIGURE 10. T2 Preparația 1.5, măsurători în sens transversal

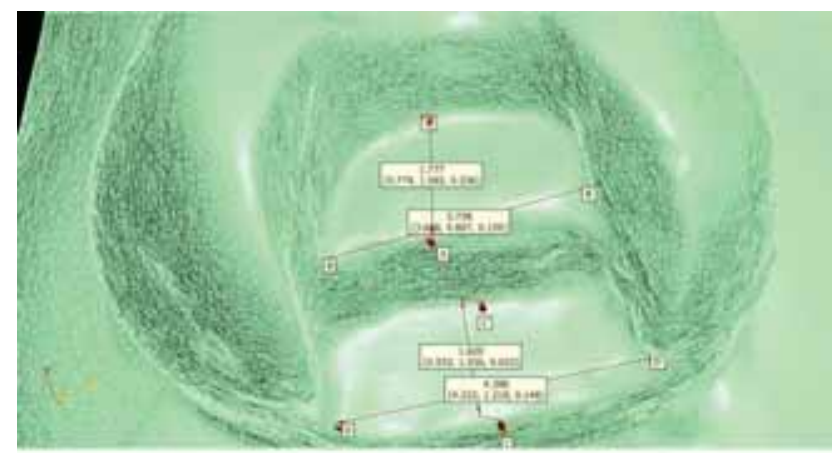

FIGURA 11. T3 Preparația 1.4, măsurători în sens sagital şi transversal

\section{REZULTATE}

În urma măsurătorilor în plan sagital şi transversal, valorile obținute pentru toate variabilele temporale au fost notate în Tabelul 1, care a fost împărțit la rândul lui în două tabele secundare, Tabelul 2 şi Tabelul 3.

Folosind aceste două tabele secundare, s-au exprimat grafic rezultatele obținute pentru toate am-

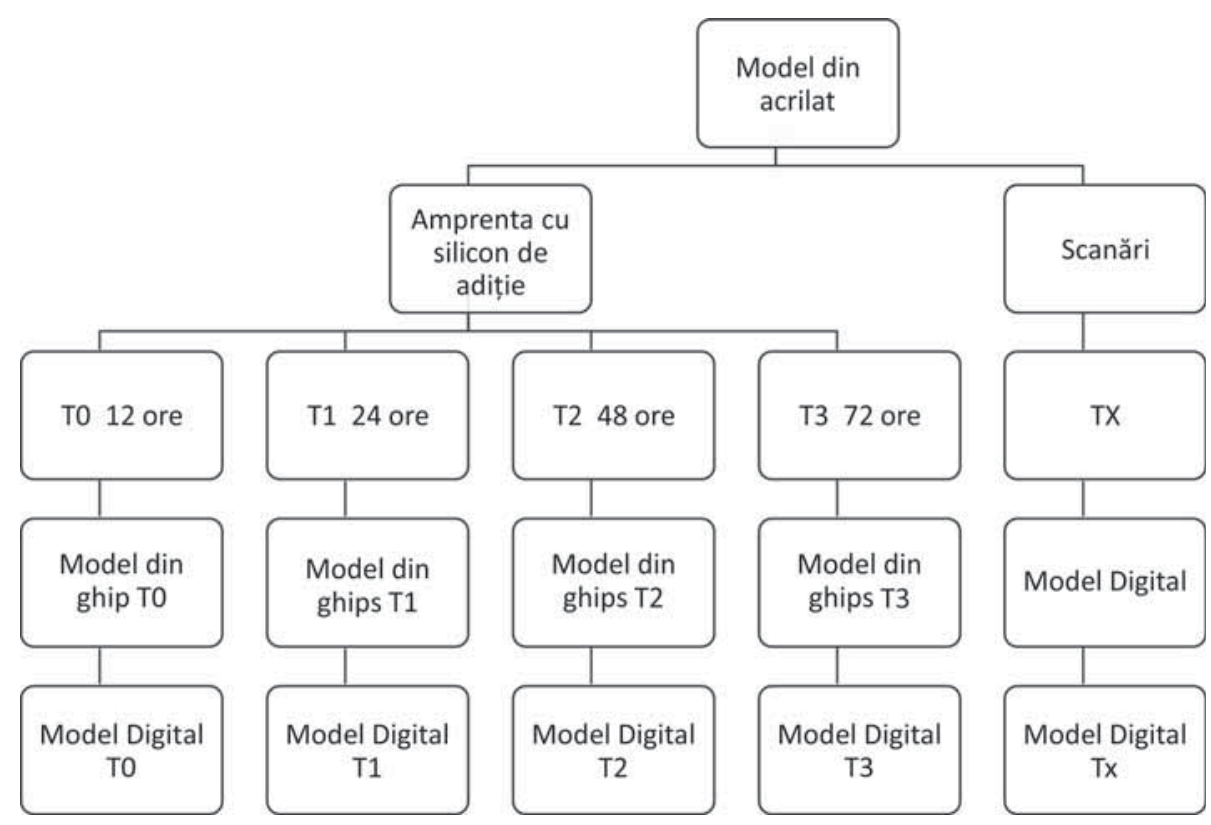

FIGURA 12. Schemă etapizată a studiului 
prentele realizate la patru timpi cu siliconul de adiție.

TABELUL 1. Măsurători în sens sagital şi transversal

\begin{tabular}{|l|c|c|c|c|c|}
\hline $\begin{array}{l}\text { Distanța dintre } \\
\text { două puncte }(\mathbf{m m})\end{array}$ & $\mathbf{T x}$ & $\begin{array}{c}\text { T0=12 } \\
\text { ore }\end{array}$ & $\begin{array}{c}\text { T1=24 } \\
\text { ore }\end{array}$ & $\begin{array}{c}\text { T2=48 } \\
\text { ore }\end{array}$ & $\begin{array}{c}\text { T3=72 } \\
\text { ore }\end{array}$ \\
\hline AA' $^{\prime}$ & 1,757 & 1,783 & 1,778 & 1,785 & 1,777 \\
\hline BB' $^{\prime}$ & 3,700 & 3,723 & 3,716 & 3,749 & 3,738 \\
\hline CC' $^{\prime}$ & 1,601 & 1,619 & 1,623 & 1,613 & 1,620 \\
\hline DD' $^{\prime}$ & 4,340 & 4,396 & 4,357 & 4,405 & 4,396 \\
\hline FF' $^{\prime}$ & 2,674 & 2,636 & 2,625 & 2,635 & 2,660 \\
\hline
\end{tabular}

TABELUL 2. Măsurători în sens sagital

\begin{tabular}{|l|c|c|c|c|c|}
\hline $\begin{array}{l}\text { Distanța dintre două } \\
\text { puncte (mm) }\end{array}$ & Tx & $\begin{array}{c}\text { T0=12 } \\
\text { ore }\end{array}$ & $\begin{array}{c}\text { T1=24 } \\
\text { ore }\end{array}$ & $\begin{array}{c}\text { T2=48 } \\
\text { ore }\end{array}$ & $\begin{array}{c}\text { T3=72 } \\
\text { ore }\end{array}$ \\
\hline AA' $^{\prime}$ & 1,757 & 1,783 & 1,778 & 1,785 & 1,777 \\
\hline CC' $^{\prime}$ & 1,601 & 1,619 & 1,623 & 1,613 & 1,620 \\
\hline
\end{tabular}

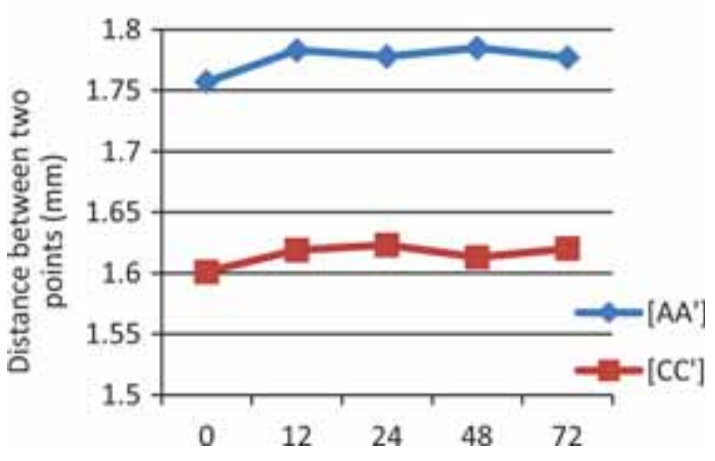

Diagrama Tabelul 2 - Plan sagital

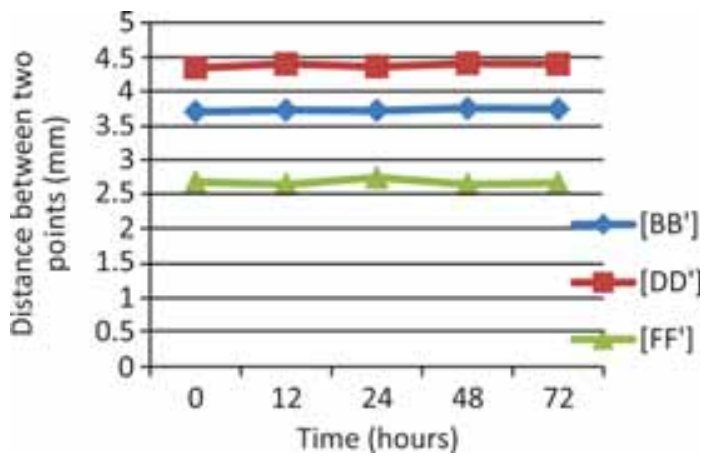

Diagrama Tabelul 3 - Plan transversal

TABELUL 3. Măsurători în sens transversal

\begin{tabular}{|l|c|c|c|c|c|}
\hline $\begin{array}{l}\text { Distanța dintre două } \\
\text { puncte (mm) }\end{array}$ & Tx & $\begin{array}{c}\text { T0=12 } \\
\text { ore }\end{array}$ & $\begin{array}{c}\text { T1=24 } \\
\text { ore }\end{array}$ & $\begin{array}{c}\text { T2=48 } \\
\text { ore }\end{array}$ & $\begin{array}{c}\text { T3=72 } \\
\text { ore }\end{array}$ \\
\hline BB' $^{\prime}$ & 3,700 & 3,723 & 3,716 & 3,749 & 3,738 \\
\hline DD' $^{\prime}$ & 4,340 & 4,396 & 4,357 & 4,405 & 4,396 \\
\hline FF' $^{\prime}$ & 2,674 & 2,636 & 2,625 & 2,635 & 2,660 \\
\hline
\end{tabular}

\section{DISCUŢII}

După analiza statistică între modelul referință la Tx şi modelele din ghips la T0, T1, T2, T3, diferen- țele pozitive şi negative ale stabilității dimensionale au fost calculate şi notate în Tabelul 4.

Folosind diagramele, se poate observa o evoluție liniară în ambele planuri, cu variații reduse de aproximativ 20 microni în sens sagital şi mai ridicate în sens transversal de până la 60 microni.

Media variațiilor în plan sagital a fost de $20 \mathrm{mi}-$ croni, reprezentând media variațiilor segmentelor AA' şi CC' la toate variabilele temporale.

Pentru planul transversal, media variațiilor a fost de 25 microni, media dintre BB', DD' şi FF' la toate momentele alese pe intervalul de timp 12-72 ore.

Exactitatea măsurătorilor pentru mediul virtual este crescută, folosindu-se coordonate pe trei axe pentru toate punctele necesare trasării segmentelor de analiză la nivelul tuturor modelelor digitale. Ca erori posibile putem considera capacitatea de înregistrare a scannerului, care este de până la 10 microni.

TABELUL 4. Mediile variațiilor

\begin{tabular}{|c|c|c|c|c|c|c|}
\hline \multirow{2}{*}{\begin{tabular}{|l|}
$\begin{array}{l}\text { Distanța } \\
\text { dintre două } \\
\text { puncte } \\
(\mathrm{mm})\end{array}$ \\
$(\mathrm{mm})$ \\
\end{tabular}} & \multicolumn{4}{|c|}{$\Delta T n=T x-T n$, unde $n=0$ la 3} & \multirow{2}{*}{$\begin{array}{c}\text { Media } \\
\Delta T\end{array}$} & \multirow[t]{2}{*}{$\begin{array}{c}\text { Media } \\
\text { generală }\end{array}$} \\
\hline & $\Delta \mathrm{TO}$ & $\Delta \mathrm{T} 1$ & $\Delta \mathrm{T} 2$ & $\Delta \mathrm{T} 3$ & & \\
\hline$A A^{\prime}$ & $-0,026$ & $-0,021$ & $-0,028$ & $-0,020$ & $-0,023$ & $-0,020$ \\
\hline BB' $^{\prime}$ & $-0,023$ & $-0,016$ & $-0,049$ & $-0,038$ & $-0,031$ & $-0,025$ \\
\hline $\mathrm{CC}^{\prime}$ & $-0,018$ & $-0,022$ & $-0,012$ & $-0,019$ & $-0,017$ & \\
\hline $\mathrm{DD}^{\prime}$ & $-0,056$ & $-0,017$ & $-0,065$ & $-0,056$ & $-0,048$ & \\
\hline $\mathrm{FF}^{\prime}$ & $+0,034$ & $-0,064$ & $+0,034$ & $+0,014$ & $+0,0045$ & \\
\hline
\end{tabular}

În final, este important de menționat şi că amprenta digitală pare a fi un subiect destul de interesant când este vorba de satisfacția pacientului. De asemenea, se dovedeşte a fi mai eficientă în comparație cu cea convențională, având în vedere confortul pacientului, timpul şi flexibilitatea pe care o oferă clinicianului cu posibilitatea de reintervenire asupra modelelor stocate, fapt sugerat şi de studiile actuale $(7,8)$.

\section{CONCLUZII}

Rezultatul acestui studiu a ilustrat precizia şi fidelitatea siliconului de adiție având ca variabilă timpul, pe un interval de timp de 12-72 ore, în comparație cu amprentarea digitală, care nu este influenţată de timp. 
Diferențele obținute în timpul măsurătorilor dintre modelele din ghips şi modelul de referință digital pot fi considerate acceptabile clinic, fiind cuprinse între 20 şi 25 microni.

Conflict of interest: none declared Financial support: none declared

\section{BIBLIOGRAFIE}

1. Radi Masri, Carl F Driscoll. Clinical Applications of Digital Dental Technology. lowa 50010, USA: John Wiley \& Sons, Inc., 2015.

2. Christensen GJ. Will digital impressons eliminate the current problems with conventional impressions? 2008, J Am Dent Association, pp. 761-763.

3. Shetty P, Rodrigues S. Accurancy of elastomeric impression materials on repeated pours. 2006, Indian Prosthodontic Society, pp. 68-71.

4. Cancy JM, Scandrett FR, Ettinger RL. Long term dimensional stability of three current elastomers. 1983, J Oral Rehabilitation, pp. 325-333.

5. Junios S. Almeida e Silvia, Kurt Erdelt, Daniel Edelhoff, Elito Araujo, Michael Stimmelmayr, Lui Clovis Cardoso Viera, Jan Frederik Guthz. Marginal and internal fit of four zirconia fixed dental protheses based on digital and conventional impression techniques. 2013, Vol. Clinic Oral INvest.

6. Sang J. Lee, Rebecca A. Betensky Grace E. Gianneschi, German O. Gallucci. Accurancy of Digital vs. Conventional Implant Impressions. 2015 Clinic Oral Implants, pp. 715-719.

7. Birnbaum, N.S. \& Aaronson H.B. Dental impression using 3D digital scanners: Virtual becomes reality, in Compendium of continuing education in dentistry, 2008, pp. 494, 496, 498-505.

8. Sang J. Lee, German O. Gallucci. Digital vs conventional implant impressions: Efficiency outcomes. 2013, Clinical Oral Implant Search, pp. 111-115.

9. Medit - Identica Blue. ExpoDental. [Online] 2015. [Cited: 03 07,2018 .] http://www.expodental.nl/medit-identica-blue-cadcam-scanner. 